Article

\title{
Protective Low-Density Polyethylene Residues from Prepreg for the Development of New Nanocomposites with Montmorillonite: Recycling and Characterization
}

\author{
Pamela Rodrigues Passos Severino ${ }^{1}$, Thaís Larissa do Amaral Montanheiro ${ }^{1,2}{ }^{\circledR}$, Orestes Ferro ${ }^{3}$, \\ Fábio Roberto Passador ${ }^{1}$ (D) and Larissa Stieven Montagna ${ }^{1, *(D)}$ \\ 1 Federal University of São Paulo (UNIFESP), Institute of Science and Technology, Technology Laboratory of \\ Polymers and Biopolymers (TecPBio), São José dos Campos, SP 12231-280, Brazil; \\ pam.passos01@gmail.com (P.R.P.S.); tlamontanheiro@gmail.com (T.L.d.A.M.); \\ fabiopassador@gmail.com (F.R.P.) \\ 2 Laboratory of Plasmas and Processes (LPP), Technological Institute of Aeronautics, Praça Marechal Eduardo \\ Gomes, 50-Vila das Acacias, São José dos Campos, SP 12228-900, Brazil \\ 3 ALLTEC, Materiais Compostos Ltda, 456 Moxotó St., São José dos Campos, SP 12238-320, Brazil; \\ orestes.ferro@allteccomposites.com.br \\ * Correspondence: larissambiental@yahoo.com.br; Tel.: +55-12-3924-9500
}

Received: 7 November 2019; Accepted: 2 December 2019; Published: 4 December 2019

\begin{abstract}
A sustainable alternative to the destination of polyethylene (PE) residue from the prepreg package was established. This work intends to develop nanocomposites for packaging containing neat low-density polyethylene (LDPE), a compatibilizer agent (maleic anhydride grafted-LDPE, LDPE- $g$-MA), recycled LDPE obtained from the protective films of prepreg (rLDPE) and montmorillonite (MMT). The rLDPE, from the prepreg shield, has a primary role during the transport and storage of prepreg, which can be composed of epoxy resin and carbon fiber or glass fiber. However, this rLDPE is withdrawn and discarded, besides, it is estimated that tons of this material are discarded monthly by the company Alltec Materiais Compostos Ltd. (São José dos Campos-SP, Brazil). Due to several factors, including the lack of technology for recycling, the majority of this material is incinerated. In this context, this work presents a technical and ecologically viable alternative for the use of this discarded material. Nanocomposites of LDPE/rLDPE blends and montmorillonite (MMT) with different contents $(0.0,1.0$, and $3.0 \mathrm{wt} \%)$ and with the addition of compatibilizer agent (LDPE- $g$-MA) were prepared by extrusion process. Test specimens were obtained by hot pressing in a hydropneumatic press followed by die-cutting. The nanocomposites produced using rLDPE presented good mechanical, thermal, and morphological properties, being the ideal concentration of $1 \mathrm{wt} \%$ MMT. Thus, the results obtained confirmed the viability of recycling LDPE from the prepreg package which contributes to the reduction of waste and the use of this material in technological applications.
\end{abstract}

Keywords: low-density polyethylene; montmorillonite; nanocomposites; recycling

\section{Introduction}

The consumption of polymeric materials has been growing in recent years. Polyethylene (PE) is a good example that besides having good properties is highly versatile, with applications in both automobiles and plastic packaging [1]. Plastic packages account for about $40 \%$ of all plastic waste and are usually destined for landfills after disposal. When this discarding is done incorrectly, several 
negative impacts can arise as a result, such as pollution of the oceans affecting marine life, emission of toxic pollutants into the atmosphere, soil contamination and water pollution, besides changes in the ecosystem [2-5]. An alternative could be incineration of residues; however, besides having a high cost involved, it generates ash residues containing heavy metals, as well as releasing dioxins and other toxic compounds, which can cause leaching, for example [4]. Unfortunately, these are the most commonly found destinations for these polymeric residues.

In addition to landfilling and incineration, a third alternative would be to recycle the plastic waste $[6,7]$. In this way, it becomes possible to use waste that would be eliminated for the preparation and development of new material, not only avoiding all the negative impacts coming from the other methods but also reducing the consumption of petroleum-based-polymer, consequently, the extraction of petroleum $[1,8,9]$.

In the literature, it is possible to find several successful research suggesting the recycling of polyethylene, mainly concerning plastic packaging [2,10]. In one of these studies, Jnr et al. [2] performed a detailed analysis of the statistics involving the disposal of polymer packages after consumption. Mechanical and rheological tests were carried out on these materials to analyze the feasibility of recycling them according to the presented properties. Another study carried out by Garofalo et al. [10] also focused on recycling flexible polymer packages, and it was suggested that the addition of nanoparticles, like nanosilicates, is an alternative to improve the mechanical properties of the recycled material. Moreover, the increase in the mechanical properties was obtained with the addition of a compatibilizer agent composed by maleic anhydride, which contributed to the compatibilization of the system. In addition to confirm the possibility of recycling into blends, the authors also found that the presence of a compatibilizer agent causes increased ductility of the material.

The presence of nanoparticles in the polymeric matrix acts as reinforcement and, due to its dimensions, provides a larger surface area between the reinforcement and the polymer matrix. Thus, good mechanical properties are achieved when the nanofiller is well dispersed into the polymer matrix [11,12]. Consequently, a lesser amount of nanofiller is required because of its low dimensions, resulting in a decrease in the mass of the material compared to traditional composites, using micrometer fillers [13].

Among the several reinforcement options, the montmorillonite nanoclay (MMT) is an interesting alternative due to the low cost allied with high availability, besides having a high degree of exfoliation and good mechanical strength $[13,14]$. However, due to hydrophilic characteristics surface modification of MMT becomes indispensable, and it is necessary to add a compatibilizer agent to assist in the interfacial interaction between the filler and the polymer, thus promoting good dispersion [13-16].

Chang [17] investigated the structures and properties of various organic/inorganic nanocomposites of low-density polyethylene (LDPE) containing MMT and maleic anhydride-grafted LDPE/MMT (LDPE-g-MA/MMT), which were produced with a twin-screw extruder and injection molding machine. The mechanical properties significantly improved when the proper amounts of MMT and MA-grafted materials were added to LDPE. This improvement in properties is mainly due to the compatibilizing effect of MA grafts.

Therefore, this work studies the feasibility of recycling polymer film waste that is used for protection and storage of prepreg (composed of epoxy resin and carbon or glass fiber). This polymer film waste is composed of low-density polyethylene (rLDPE) and is widely used in the composite industry, mainly in the city of São José dos Campos (Brazil), which owns the largest Brazilian aircraft company. The main goal of this work is to prepare LDPE/rLDPE blend-based MMT nanocomposites using MA-grafted LDPE (LDPE- $g$-MA) as a compatibilizer agent. The objective is to find a sustainable and less harmful alternative to the destination of this polymer residue, applying the new material in technological applications. 


\section{Experimental}

\subsection{Materials}

Low-density polyethylene film waste (rLDPE) was supplied by Alltec Materiais Compostos Ltd. (São José dos Campos-SP/Brazil). Low-density polyethylene (LDPE, LD $5000 \mathrm{~A}$ ) with a melt index of $1.4 \mathrm{~g} / 10 \mathrm{~min}\left(190^{\circ} \mathrm{C} / 2.16 \mathrm{~kg}\right)$ was supplied by Braskem, Brazil. Benzoyl peroxide (BPO) supplied by Contemporary Chemistry Dynamics and Maleic Anhydride (MA) (Aldrich with 99\% purity) were used for the production of compatibilizer agent LDPE-g-MA. Montmorillonite clay (MMT) was supplied as Cloisite ${ }^{\circledR} 20$ A by Southem Clay Products Inc (Gonzales, TX, USA). This MMT was ion-exchanged with dimethyl dihydrogenated tallow ammonium ions, where tallow was composed predominantly of octadecyl chains with a smaller amount of lower homologs. The approximate composition was C18 (65\%), C16 (30\%), and C14 (5\%). This organoclay was selected based upon recent studies showing improved organoclay exfoliation in PE using surfactants with two tails on the ammonium ion instead of one tail $[15,18]$.

\subsection{Preparation of Compatibilizer Agent (LDPE-g-MA)}

To enable the preparation of the LDPE/rLDPE/MMT nanocomposites, it was necessary to prepare a compatibilizer to allow the formation of intercalated layers of MMT in the polymer chains, avoiding their agglomeration and poor dispersion in the matrix of LDPE/rLDPE [19].

A co-rotational double screw extruder from AX Plásticos, model AX16:40DR (L/D = 40, D = $16 \mathrm{~mm}$ ) was used, with the temperature profile of $170 / 180 / 180 / 190 / 190{ }^{\circ} \mathrm{C}$, from the first section to the die, operating at a screw rotation speed of $100 \mathrm{rpm}$ and feeding of $20 \mathrm{rpm}$. LDPE-g-MA was produced with the addition of $96 \mathrm{wt} \%$ of LDPE, $2 \mathrm{wt} \%$ of MA, and $2 \mathrm{wt} \%$ of BPO, which was used as the initiator. The reaction occurred during the extrusion process, being noticed by the change in the coloration of the extruded material, resulting in the granulated material in the form of pellets.

\subsection{Preparation of rLDPE by Milling of the LDPE Films Waste}

rLDPE was received in films, and was milled for the production of the nanocomposites. In this way, the cryogenic milling of the material was done using an analytical mini-mill (IKA A11). This procedure was necessary to obtain the material in powder, which is the strategy required for processing in the extruder. Figure 1 shows rLDPE before and after the milling process.

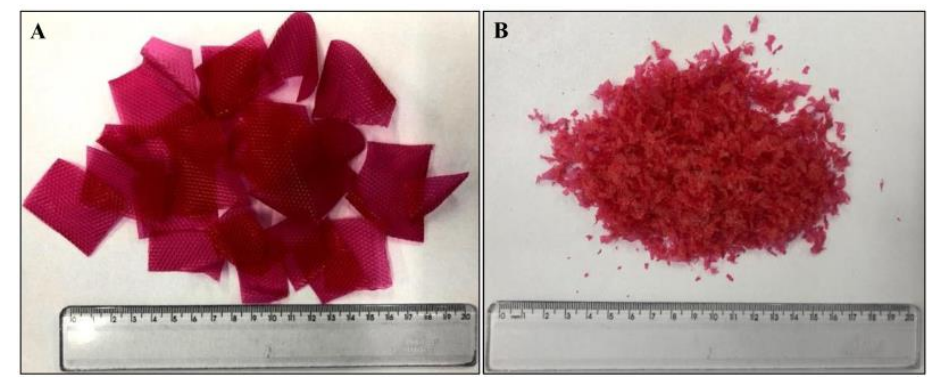

Figure 1. Preparation of prepreg low-density polyethylene (rLDPE): material as received by Alltec Materiais Compostos Ltd. (São José dos Campos-SP, Brazil) (A) and after cryogenic milling (B).

\subsection{Sample Processing}

Prior to processing, the MMT was oven-dried at $60^{\circ} \mathrm{C}$ for $24 \mathrm{~h}$. LDPE/LDPE- $g$-MA/MMT and LDPE/LDPE-g-MA/rLDPE/MMT nanocomposites with different contents of MMT (0.0, 1.0, and $3.0 \mathrm{wt} / \%$ ) were prepared by melt blending in a co-rotational double screw extruder from AX Plásticos, model AX16:40DR. The temperature profile was 170/180/180/190/190 ${ }^{\circ} \mathrm{C}$ from the first section to the die, operating at a screw rotation speed of $120 \mathrm{rpm}$ and feeding of $30 \mathrm{rpm}$. The compositions used are 
shown in Table 1. The final blend nanocomposites were prepared with a ratio of 1:1 (LDPE/rLDPE) and $5 \mathrm{wt} \%$ of compatbilizer agent (LDPE-g-MA).

Table 1. Composition and designation of nanocomposites.

\begin{tabular}{ccccc}
\hline Samples Composition & LDPE (\%) & LDPE- $g$-MA (wt\%) & rLDPE (\%) & MMT (wt/\%) \\
\hline 50LDPE/50rLDPE/0M & 50 & 5 & 50 & 0 \\
50LDPE/50rLDPE/1M & 50 & 5 & 50 & 1 \\
50LDPE/50rLDPE/3M & 50 & 5 & 50 & 3 \\
100LDPE/0M & 100 & 5 & 0 & 0 \\
100LDPE/1M & 100 & 5 & 0 & 1 \\
100LDPE/3M & 100 & 5 & 0 & 3 \\
\hline
\end{tabular}

After homogenizing the blends nanocomposites by an extrusion process, the samples were granulated and standardized specimens were molded into 3.2. $\mathrm{mm}$ thick plates in a hydropneumatic press (MH Equipamentos, Guarulhos, Brazil, model PR8H) at $190^{\circ} \mathrm{C}$ with a pressure of 5 bar for $3 \mathrm{~min}$. Standardized specimens for the impact and tensile tests were prepared using a pneumatic hollow die punch machine (CEAST/Instron).

\section{Composites Obtained: Characterization}

The following sections will present the characterizations and comparisons made of the composites obtained using recycled material (rLDPE) and only with virgin material (LDPE from Braskem).

\subsection{X-Ray Diffraction (XRD)}

The phase composition of MMT was analyzed by X-ray diffraction (PANalytical EMPYREAN) with $\mathrm{Cu}-\mathrm{K} \alpha$ radiation $(\lambda=1.5406 \AA)$ in the $2 \theta$ range $5-50^{\circ}$ at a scan rate of $0.6 \mathrm{~s} / \mathrm{step}$. The operating current and voltage were set at $40 \mathrm{~mA}$ and $40 \mathrm{kV}$, respectively.

\subsection{FT-IR/UATR}

Grafting reaction of maleic anhydride to LDPE and the nanocomposites samples were evaluated by FT-IR, recorded on a Frontier spectrometer (PerkinElmer, Waltham, MA, USA), equipped with a universal attenuated total reflection (UATR) accessory. Each spectrum was acquired in transmittance mode by accumulation of 20 scans with a range of $4000-400 \mathrm{~cm}^{-1}$.

\subsection{Differential Scanning Calorimetry (DSC)}

DSC analyses were performed on a Netzsch Phoenix ${ }^{\circledR}$ DSC 204 F1. Small amounts $(10 \mathrm{mg})$ of dried samples were placed into aluminum pans. The heating rate of $10{ }^{\circ} \mathrm{C} \mathrm{min}-1$ from 25 to $200{ }^{\circ} \mathrm{C}$, in nitrogen atmosphere with a gas flow of $20 \mathrm{~mL} \mathrm{~min}^{-1}$ to obtain the melting point (Tm) and the enthalpy of fusion directly obtained by DSC $(\Delta H m)$, in a single heating. The crystalline content $(\mathrm{Xc})$ was calculated by Equation (1), where the melting enthalpy of the $100 \%$ crystalline LDPE $\left(\Delta H m^{\circ}\right)$ was taken as $293 \mathrm{~J} / \mathrm{g}$ [20], $\Delta H c$ is the crystallization enthalpy during heating that in this case is $0 \mathrm{~J} / \mathrm{g}, \varnothing$ is the volume fraction of the MMT in the polymer. $T m, \Delta H m$, and Xc were obtained during second heating scans for all compositions.

$$
X c(\%)=\frac{\Delta H m-\Delta H c}{\Delta H m^{\circ} \cdot \varnothing_{\text {Montmorillonite }}} \cdot 100
$$

\subsection{Scanning Electron Microscopy (SEM)}

The cryogenic fracture surface morphology of the samples was observed by scanning electron microscopy (SEM) using an Inspect S50 FEI Company ${ }^{\circledR}$ microscope, with detectors of secondary 
electrons mode (SE), an accelerating voltage of $15 \mathrm{kV}$, and with magnification of 10.000×. The samples were cryogenically fractured, fixed on aluminum stubs, and covered with gold.

\subsection{Mechanical Properties}

The mechanical properties of the samples were determined by Izod impact test, tensile tests, and Shore D hardness test. The Izod impact test was performed on a CEAST/Instron Izod impact testing machine (model 950), with a $5.5 \mathrm{~J}$ hammer and sample dimensions: length $63.5 \mathrm{~mm}$; width $12.7 \mathrm{~mm}$; $3.28 \mathrm{~mm}$ thickness. The test method was carried out according to ASTM D256-06. All the test specimens were notched using a manual notching machine (CEAST/Instron), with a depth of $2.54 \pm 0.1 \mathrm{~mm}$. Tensile tests were carried out according to ASTM D638 using a Universal testing machine (EMIC, model DL20.000) at a crosshead speed of $50 \mathrm{~mm} \mathrm{~min}^{-1}$ and sample dimensions: length $165 \mathrm{~mm}$; thickness $3.28 \mathrm{~mm}$; working length $57.0 \mathrm{~mm}$ and narrow section width 13.0. A minimum of 5 specimens for each composition was tested. The specimens were submitted to Shore D hardness test using a digital Shore D hardness tester (Instrutherm, Model DP-400). Measurements were performed on the surface of the samples, at distant points. The experiment was accomplished according to ASTM D790.

\section{Results and Discussion}

\subsection{XRD: MMT and Nanocomposites}

Figure 2 shows the diffraction pattern for MMT and the nanocomposites. For neat MMT, characteristic peaks are observed at $2 \theta=7.09^{\circ}$ and $2 \theta=19.82^{\circ}$. The peak at $2 \theta=19.82^{\circ}$ is characteristic for nonbasal reflections, due to the layered structure [21]. In the samples with $3 \mathrm{wt} \%$ of MMT, it can be observed that the MMT characteristic peak shifts to lower angles if compared to the peak of the pristine organoclay (which was at $2 \theta=7.09^{\circ}$ for neat MMT), suggesting intercalation of the polymer molecules into the galleries of the clay. The results indicated that an intercalated structure in the compatibilized nanocomposites was predominant. For $100 \mathrm{PE} / 3 \mathrm{M}$, the peak was shifted to $2 \theta=6.77^{\circ}$, and for 50LDPE/50rLDPE/3M, the peak was shifted to $2 \theta=6.57^{\circ}$. It was not possible to obtain the curve for angles smaller than $5^{\circ}$, so the composition with $1 \mathrm{wt} \%$ MMT did not present the MMT characteristic peak. The absence of this peak in the samples with $1 \mathrm{wt} \%$ of MMT suggests that the MMT has nearly exfoliated into the matrix [22].
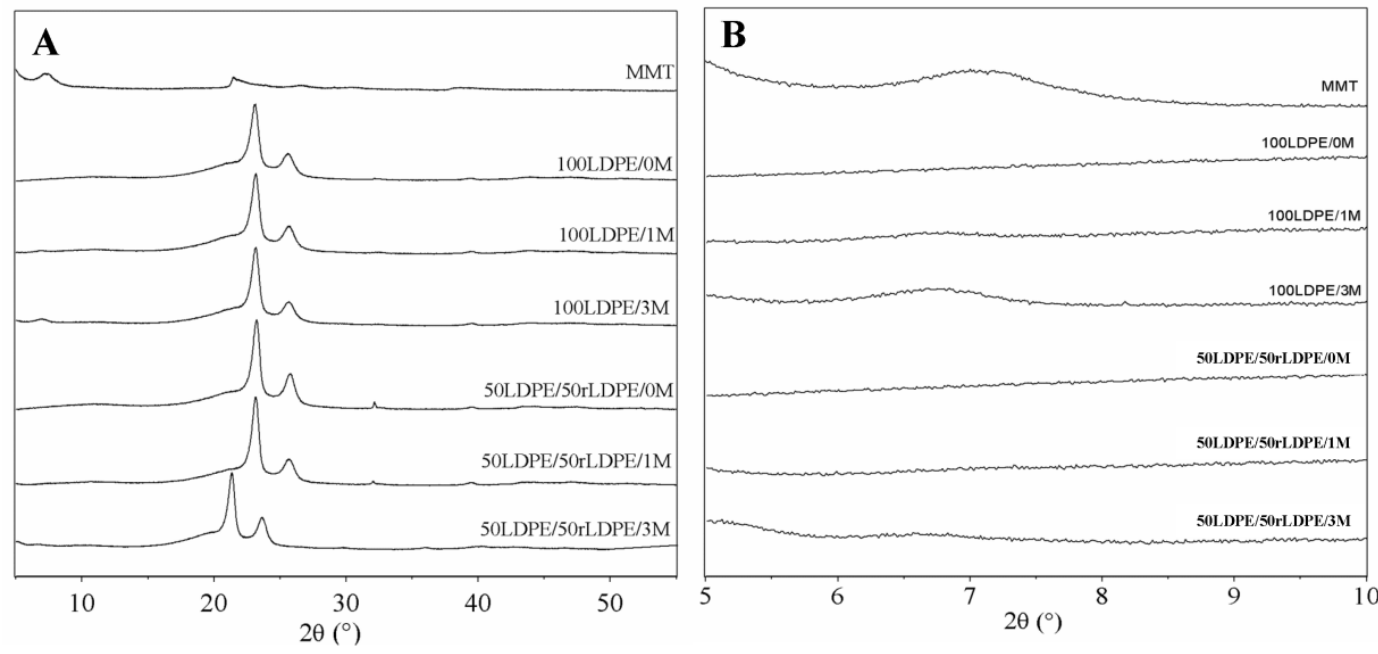

Figure 2. X-Ray diffraction spectra of montmorillonite (MMT) and nanocomposites with LDPE and rLDPE. (A), $10-50^{\circ} ;(\mathbf{B}), 5-10^{\circ}$. 


\subsection{FT-IR/UATR}

Figure 3 shows the FT-IR spectra of neat LDPE, rLDPE, and LDPE-g-MA. Neat LDPE and rLDPE spectra show the well-known main absorption bands at 2914, 2847, $1461,719 \mathrm{~cm}^{-1}$, attributed to $\mathrm{CH}_{2}$ and $\mathrm{CH}$ vibrations [23]. The LDPE- $g$-MA spectrum shows all the absorption bands found on LDPE, added to new absorption bands at 1682, 1581, 1287, and $929 \mathrm{~cm}^{-1}$, due to anhydride functions $[24,25]$.

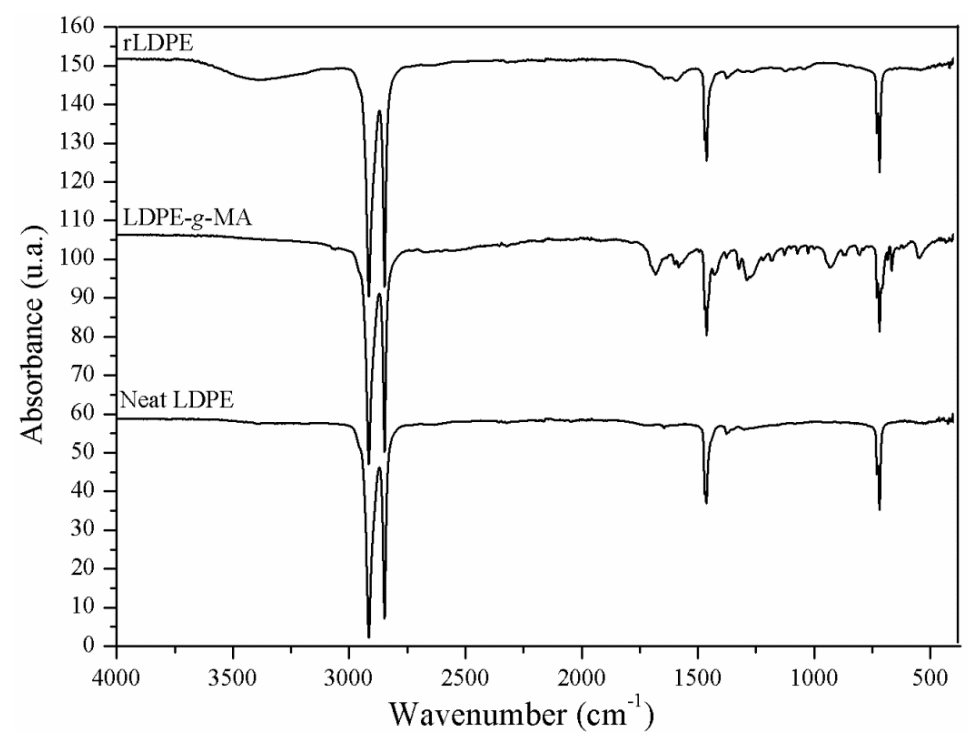

Figure 3. FT-IR spectra of neat LDPE, rLDPE, and LDPE- $g$-MA.

Figure 4 shows the FT-IR spectra of MMT, neat LDPE, and nanocomposites. MMT shows the main absorption band at $1005 \mathrm{~cm}^{-1}$, attributed to Si-O stretch [26]. The presence of MMT is slightly observed in the composites spectra, through the presence of a small shoulder at $1035 \mathrm{~cm}^{-1}$. The shift in the MMT characteristic band to higher wavelengths $\left(1005\right.$ to $\left.1035 \mathrm{~cm}^{-1}\right)$ means that there may exist interactions as hydrogen bonding between the matrix and the MMT [27], possibly because of the incorporation of LDPE-g-MA in all samples. It can be observed that samples without MMT did not show the shoulder at $1035 \mathrm{~cm}^{-1}$. These results prove that maleic anhydride was satisfactorily grafted to LDPE chains and, more than that, acted as an active compatibilizer agent between the neat polymer and MMT nanoparticles, promoting a good interaction between them.

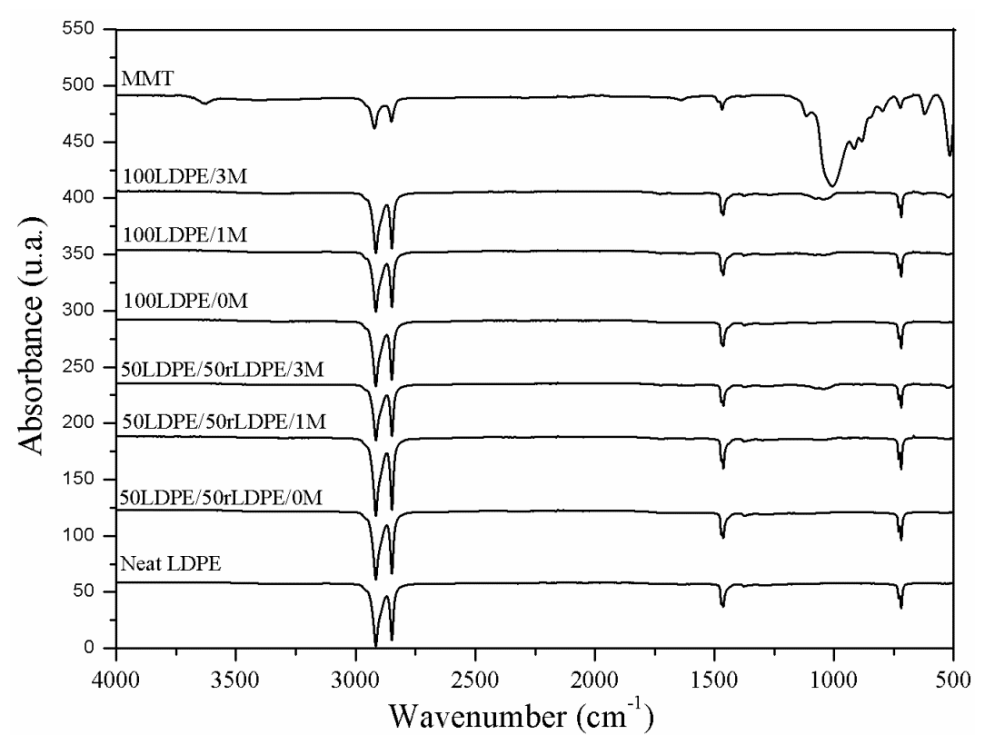

Figure 4. FT-IR spectra of MMT, neat LDPE, and nanocomposites. 


\subsection{Thermal, Morphological and Mechanical Characterization}

Figure 5 shows the thermograms obtained by DSC. Figure 5 A shows the thermogram of neat rLDPE, Figure 5B the neat LDPE and LDPE- $g$-MA, and Figure 5C the thermograms of the nanocomposites. All the data were collected from the second heating scan. For better visualization and comparison of the results from DSC thermal analysis, melting point $\left(\mathrm{T}_{\mathrm{m}}\right)$, melting enthalpy $\left(\Delta \mathrm{H}_{\mathrm{m}}\right)$ and degree of crystallinity $\left(X_{c}\right)$ are shown in Table 2 .
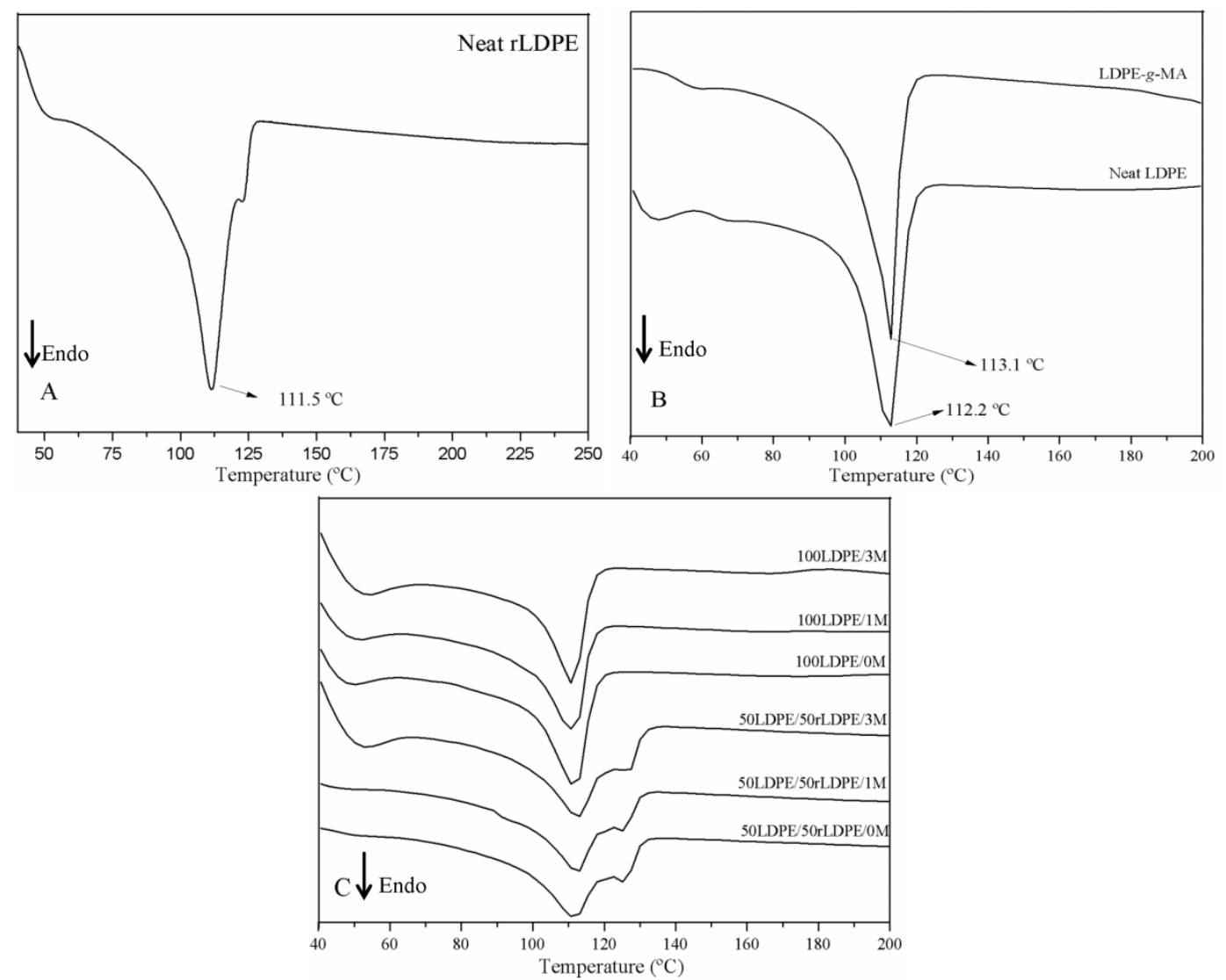

Figure 5. Differential Scanning Calorimetry (DSC) thermograms of neat rLDPE (A), neat LDPE, and LDPE- $g$-MA (B), and the nanocomposites (C).

Table 2. Results obtained by DSC analysis by the second heating cycle.

\begin{tabular}{cccc}
\hline Samples & $\boldsymbol{T}_{\boldsymbol{m}}\left({ }^{\circ} \mathbf{C}\right)$ & $\Delta \boldsymbol{H}_{\boldsymbol{m}}(\mathrm{J} / \mathbf{g})$ & $\boldsymbol{X}_{\boldsymbol{C}}(\mathbf{\%})$ \\
\hline Neat rLDPE & 112 & 100.4 & 34.3 \\
Neat LDPE & 112 & 76.86 & 26.2 \\
LDPE-g-MA & 113 & 84.28 & 28.8 \\
50LDPE/50rLDPE/0M & 112 & 98.38 & 33.6 \\
50LDPE/50rLDPE/1M & 112 & 96.52 & 34.0 \\
50LDPE/50rLDPE/3M & 112 & 98.93 & 34.5 \\
100LDPE/0M & 112 & 84.78 & 28.9 \\
100LDPE/1M & 111 & 81.94 & 28.2 \\
100LDPE/3M & 110 & 73.06 & 25.7 \\
\hline
\end{tabular}

Samples containing neat LDPE in the composition showed a single $\mathrm{T}_{\mathrm{m}}$ peak at about $100{ }^{\circ} \mathrm{C}$, but when analyzing the samples containing $50 \%$ of rLDPE and $50 \%$ of neat LDPE, it is possible to observe the presence of a shoulder on this peak, at about $125^{\circ} \mathrm{C}$. This shoulder can be justified by the fact that rLDPE already has undergone primary processing, once it is recycled material. Recycled materials have some thermal properties modified when being reused, so this second melting peak 
is possibly a result of this modification. Moreover, since the return to solid-phase polymer would achieve a new structural configuration different from that which existed previously, the double melting peaks may be a result of morphological variations or from recrystallization-re-melting processes of the material $[1,28,29]$.

It is also possible to observe in the thermograms (Figure 5C) that the addition of MMT into the polymer matrix resulted in a slight broadening of the endothermic crystalline melting peak. This fact may be related to the incorporation of MMT into the matrix of neat LDPE/rLDPE because MMT is a layered silicate that causes a strong effect on the structure and the crystallization process, causing a restriction in the chain folding, and a disturbance in the formation of the crystals [30,31].

Regardless of the MMT content added in the polymer matrix, it was not possible to detect changes in $T_{m}$ characteristics when comparing all the samples. Therefore, the presence of MMT does not appear to interfere in the intermolecular forces of the polymer chains, since there was no change in melt temperatures. The same behavior was observed by Lee et al. [30] which synthesized PE/MMT by in situ polymerization and observed no change in the $T_{m}$ values of neat $P E$ when compared with PE/MMT nanocomposites. Other authors who verified the non-alteration of $\mathrm{T}_{\mathrm{m}}$ with the addition of MMT in the polymer matrix of PE were Golebiewski et al. [32]. In this way, the values presented are in agreement with $\mathrm{T}_{\mathrm{m}}$ values $\left(120^{\circ} \mathrm{C}\right)$ shown in the literature for LDPE [28].

According to $X_{c}$ results shown in Table 2, the samples 50LDPE/50LDPE rec $_{0} 0 \mathrm{M}$, 50LDPE/50rLDPE/1M, and 50LDPE/50rLDPE/3M, which contain rLDPE in the composition, presented crystallinity very close to neat rLDPE. Moreover, the addition of MMT resulted in a slight increase in the crystallinity values of the nanocomposites. This may indicate that, although this increase in crystallinity obtained is not very expressive, it may have caused the intercalation of the MMT with the polymer chain, since with this arrangement the organization is conserved. Therefore, the increase in the degree of crystallinity is justified because MMT acts as a nucleating agent in the polymer [33].

Figure 6 shows SEM micrographs of the cryogenic fracture surface of the samples (50LDPE/50rLDPE/0M, 50LDPE/50rLDPE/1M, 50LDPE/50rLDPE/3M, 100LDPE/0M, 100LDPE/1M, and $100 \mathrm{LDPE} / 0 \mathrm{M}$ ) with a magnification of $10.000 \times$. There is a similarity in all micrographs since the samples presented resembling cryogenic surface morphology. However, it is noted that MMT is probably well dispersed in the polymer matrix since the formation of agglomerates was not identified. Furthermore, the nanocomposites micrographs resemble much of the samples without the addition of MMT, Figure 6 A-D, reinforcing the possibility of good MMT dispersion in the polymer matrix. The good miscibility of the rLDPE/LDPE/LDPE-g-MA blend was confirmed (Figure $6 \mathrm{~A}-\mathrm{C}$ ) since the formation of a single-phase was observed. Moreover, it is not possible to identify the presence of pores in the structures.

Comparing the samples with (Figure $6 \mathrm{~A}-\mathrm{C}$ ) and without (Figure $6 \mathrm{D}-\mathrm{F}$ ) rLDPE in the formulation, regardless of the MMT contents $(0,1$ and $3 \mathrm{wt} \%)$, a morphological similarity is observed, which is a good indication of the viability of using recycled polyethylene to obtain nanocomposites of rLDPE/LDPE blends/LDPE- $g$-MA and MMT.

Table 3 shows the mechanical test results of the samples (50PE/50rLDPE/0M, 50PE/50rLDPE/1M, 50PE/50rLDPE/3M, 100PE/0M, 100PE/1M, and 100PE/0M). Changes in the values of the mechanical properties analyzed were verified, but all values obtained are close to the standard deviation. The Izod impact strength (IS) was improved for samples with rLDPE in the composition. The presence of rLDPE in the nanocomposites led to an increase of approximately $11 \%$ in the values of impact strength when compared to nanocomposites containing only the neat LDPE matrix, but this increase is close to the error range (standard deviation). Moreover, it was also possible to observe that the IS values have a decreasing trend of $1.7 \%$ and $5.6 \%$ for 50LDPE/50rLDPE/1M and 50LDPE/50rLDPE/3M, respectively, in SI values, probably due to the increase in MMT content. 

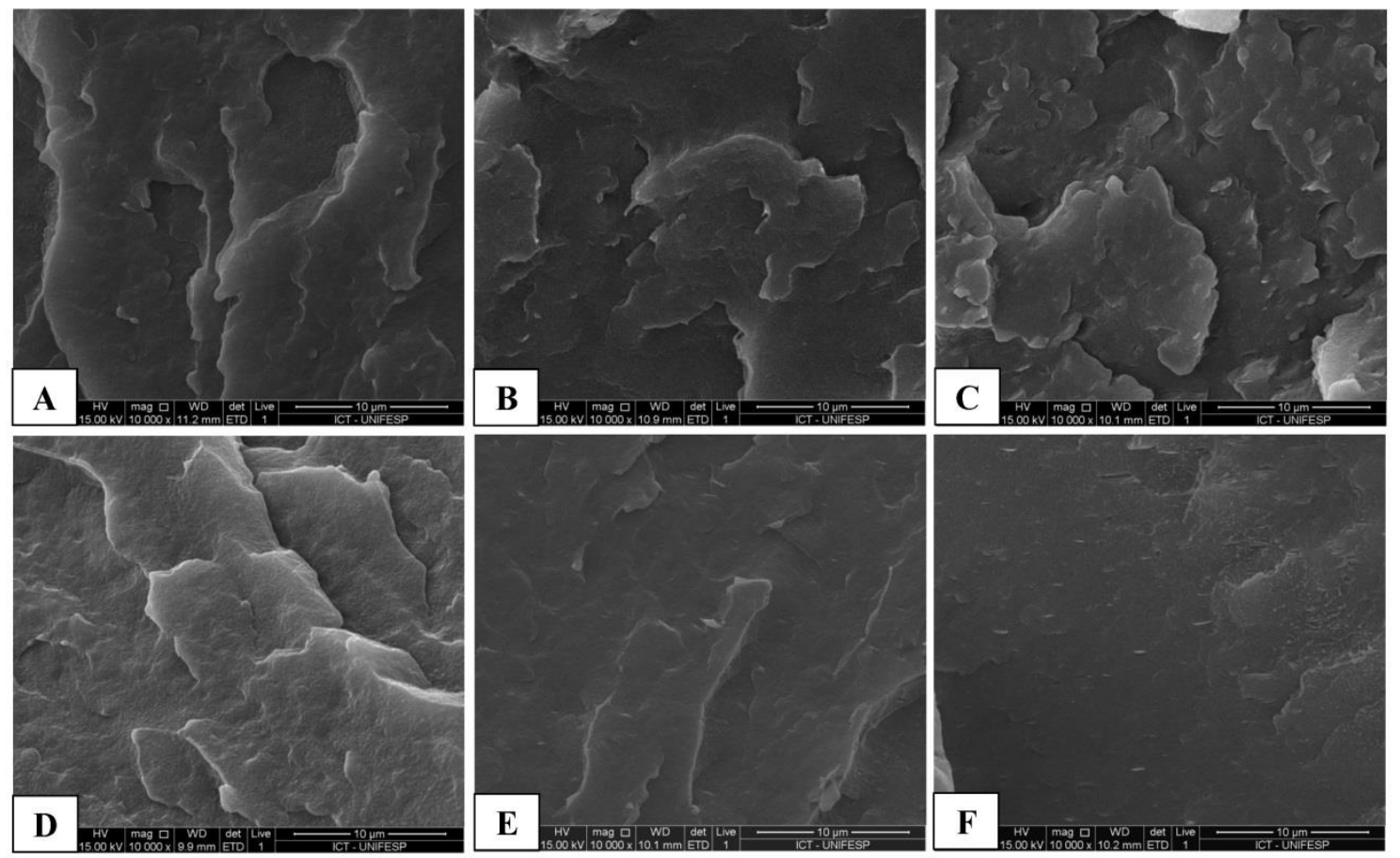

Figure 6. Scanning Electron Microscopy (SEM) micrographs of cryogenic surface fracture: 50LDPE/50rLDPE/0M (A), 50LDPE/50rLDPE/1M (B), 50LDPE/50rLDPE/3M (C), 100LDPE/0M (D), 100LDPE/1M (E), and 100LDPE/0M (F), with a magnification of 10.000x.

Table 3. Values of Izod impact strength (IS), ultimate tensile strength (UTS), Young's modulus (E), and shore D hardness for the samples.

\begin{tabular}{ccccc}
\hline Samples & IS $(\mathbf{J} / \mathbf{m})$ & UTS $\mathbf{( M P a )}$ & E $(\mathbf{M P a})$ & Shore D Hardness \\
\hline 50LDPE/50rLDPE/0M & $40.45 \pm 2.81$ & $9.5 \pm 0.1$ & $88.20 \pm 14.86$ & $52.64 \pm 1.09$ \\
50LDPE/50rLDPE/1M & $39.75 \pm 0.46$ & $9.6 \pm 0.3$ & $54.93 \pm 11.03$ & $56.09 \pm 0.89$ \\
50LDPE/50rLDPE/3M & $38.17 \pm 2.55$ & $9.6 \pm 0.1$ & $47.25 \pm 6.01$ & $54.84 \pm 1.07$ \\
100LDPE/0M & $34.31 \pm 3.42$ & $8.4 \pm 0.1$ & $53.70 \pm 12.01$ & $52.07 \pm 0.88$ \\
100LDPE/1M & $36.81 \pm 7.30$ & $8.7 \pm 0.7$ & $54.75 \pm 10.83$ & $52.37 \pm 0.91$ \\
100LDPE/3M & $34.59 \pm 3.57$ & $8.4 \pm 0.1$ & $51.88 \pm 5.05$ & $51.51 \pm 0.94$ \\
\hline
\end{tabular}

Regarding tensile strength (UTS), it was also possible to observe an increase in $10 \%$ for the samples containing rLDPE. Concerning the different contents of MMT ( 1 and $3 w t \%)$, due to the standard deviation, similar values of tension strength are obtained for all compositions using rLDPE. However; nanocomposites containing only neat LDPE matrix exhibited an improvement in the tensile properties with the addition of $1 \mathrm{wt} \%$ MMT, but with higher contents $(3 \mathrm{wt} \%)$ there was a decrease in tensile strength values.

According to the research conducted by Liu and Tu [34], the introduction of MMT into polymer matrix does effectively affect the tensile properties of a pristine polymer. However, the decrease in tensile strength may be due to the aggregation of MMTs and MAs in nanocomposites. However, in the present work, a small increase in the tensile strength values was observed, with values which are in accordance with the standard deviation presented. Moreover, in SEM images (Figure 6), it was not possible to identify aggregates/agglomerates of MMT.

The Young's modulus is an indicator of the stiffness of the samples, in this way corresponds to the region in which the increase in elongation is reversible and proportional to the deformation. Accordingly, it was possible to observe that the presence of rLDPE and MMT influenced Young's modulus of the nanocomposites. The 50LDPE/50rLDPE/0M sample had a high Young's modulus of $88.20 \mathrm{MPa}$, indicating lower ductility and consequently greater brittleness. However, when incorporating MMT in 
the composition, a gradual reduction of approximately $38 \%$ and $46 \%$ in Young's modulus values was observed for 50LDPE/50rLDPE/1M and 50LDPE/50rLDPE/3M, respectively.

Moreover, this increase in the Young's modulus observed for the samples produced with rLDPE occurs because the addition of MMT provides an increase in rigidity of the test specimens, acting as reinforcement, which was expected [35].

The samples containing only the neat LDPE matrix presented similar values of Young's modulus, meaning that the rigidity of these samples did not show significant changes after the addition of MMT.

In this way, it is observed that the values of the mechanical properties are in agreement with the values of the degree of crystallinity presented in Table 2. Samples with rLDPE in the composition presented the best results in the analyzed mechanical properties, and consequently the highest values of $X_{c}$.

Table 3 also shows the Shore D hardness values of the samples. The hardness values of all the analyzed samples are close to 49 Shore D, the value presented in the literature for the LDPE [36]. The addition of MMT increased the penetration resistance of the nanocomposites, specifically, increased hardness values by approximately $8 \%$. This increase is more evident in samples containing rLDPE in the composition. This fact was already expected since MMT is a highly hard ceramic material, which consequently transferred part of this characteristic to the LDPE matrix $[35,37]$.

\section{Conclusions}

The production of LDPE nanocomposites with MMT using $50 \mathrm{wt} \%$ recycled material, which is industrial waste, was successfully handled. The results showed the feasibility of reuse and recycling of polymer film waste (rLDPE) for the development of nanocomposites with good thermal, mechanical, and morphological characteristics, which presented values equal and/or superior to virgin neat material (neat LDPE) used as a comparative. The addition of MMT caused an increase in crystallinity degree values due to the nucleating effect of MMT. Samples produced using rLDPE in the composition showed improved mechanical properties, compared to neat LDPE. The homogeneity and interaction between the neat LDPE, rLDPE, and the MMT were satisfactory, and no alteration or discontinuity was verified on the analyzed surfaces. Given the numerous environmental problems and impacts of polymer waste pollution, the development of new materials from waste and tailings must be prioritized, to bring numerous benefits to our planet and the world's health.

Author Contributions: Conceptualization, P.R.P.S. and L.S.M.; methodology, P.R.P.S.; T.L.d.A.M.; F.R.P. and L.S.M.; validation, L.S.M.; O.F. and F.R.P.; formal analysis, P.R.P.S.; T.L.d.A.M.; F.R.P. and L.S.M.; investigation, P.R.P.S.; T.L.d.A.M.; F.R.P.; O.F. and L.S.M.; resources, O.F. data curation, P.R.P.S.; F.R.P.; O.F. and L.S.M.; writing—original draft preparation, P.R.P.S.; T.L.d.A.M.; F.R.P. and L.S.M.; writing-review and editing, L.S.M.; visualization, P.R.P.S.; T.L.d.A.M.; F.R.P.; O.F. and L.S.M.; supervision, L.S.M.; project administration, L.S.M.; funding acquisition, F.R.P. and O.F.

Funding: The authors would like to thank the Brazilian Funding institutions CNPq (405675/2018-6 and 310196/2018-3), FAPESP (2016/19978-9) and Alltec Company for the financial support.

Acknowledgments: We would also thank the NAPCEM for the use of DSC and MEV facility.

Conflicts of Interest: The authors declare that they have no conflict of interest.

\section{References}

1. Soto, J.M.; Blázquez, G.; Calero, M.; Quesada, L.; Godoy, V.; Martín-lara, M.Á. A real case study of mechanical recycling as an alternative for managing of polyethylene plastic film presented in mixed municipal solid waste. J. Clean. Prod. 2018, 203, 777-787. [CrossRef]

2. Jnr, A.K.; Yunana, D.; Kamsouloum, P.; Webster, M.; Wilson, D.C.; Cheeseman, C. Recycling waste plastics in developing countries: Use of low-density polyethylene water sachets to form plastic bonded sand blocks. Waste Manag. 2018, 80, 112-118.

3. Vaverková, M.D.; Winkler, J.; Adamcová, D.; Radziemska, M.; Uldrijan, D.; Zloch, J. Municipal solid waste land fi ll-Vegetation succession in an area transformed by human impact. Ecol. Eng. 2019, 129, 109-114. [CrossRef] 
4. Luo, H.; Cheng, Y.; He, D.; Yang, E.H. Science of the Total Environment Review of leaching behavior of municipal solid waste incineration. Sci. Total Environ. 2019, 668, 90-103. [CrossRef] [PubMed]

5. Horodytska, O.; Valdés, F.J.; Fullana, A. Plastic flexible films waste management-A state of art review. Waste Manag. 2018, 77, 413-425. [CrossRef] [PubMed]

6. Hou, P.; Xu, Y.; Taiebat, M.; Lastoskie, C.; Miller, S.A. Life cycle assessment of end-of-life treatments for plastic fi lm waste. J. Clean. Prod. 2018, 201, 1052-1060. [CrossRef]

7. Wagner, T.P.; Science, E.; Maine, S.; States, U. Sustainability and Plastic Waste; Elsevier: Amsterdam, The Netherlands, 2018.

8. Matar, S.; Hatch, L.F. Synthetic Petroleum-Based Polymers. In Chemistry of Petrochemical Processes, 2nd ed.; Elsevier: Amsterdam, The Netherlands, 2001; pp. 323-373.

9. Rahimi, A.; García, J.M. Chemical recycling of wast plastic for new materials production. Nat. Rev. Chem. 2017, 1, 0046. [CrossRef]

10. Garofalo, E.; di Maio, L.; Scarfato, P.; di Gregorio, F.; Incarnato, L. Reactive compatibilization and melt compounding with nanosilicates of post-consumer fl exible plastic packagings. Polym. Degrad. Stab. 2018, 152, 52-63. [CrossRef]

11. Scarfato, P.; Incarnato, L.; di Maio, L.; Dittrich, B. Influence of a novel organo-silylated clay on the morphology, thermal and burning behavior of low density polyethylene composites. Compos. Part B 2016, 98, 444-452. [CrossRef]

12. Peponi, L.; Puglia, D.; Torre, L.; Valentini, L.; Kenny, J.M. Processing of nanostructured polymers and advanced polymeric based nanocomposites. Mater. Sci. Eng. R Rep. 2014, 85, 1-46. [CrossRef]

13. Muñoz-Shugulí, C.; Rodríguez, F.J.; Bruna, J.E.; Galotto, M.J.; Sarantópoulos, C.; Perez, M.A.F.; Padula, M. Cetylpyridinium bromide-modified montmorillonite as filler in low density polyethylene nanocomposite films. Appl. Clay Sci. 2019, 168, 203-210. [CrossRef]

14. Bee, S.L.; Abdullah, M.A.A.; Bee, S.T.; Sin, L.T.; Rahmat, A.R. Polymer nanocomposites based on silylated-montmorillonite: A Review. Prog. Polym. Sci. 2018, 85, 57-82. [CrossRef]

15. Pessan, L.A.; Passador, F.R.; Coll, A. Structural, Thermal, and Gas Transport Properties of HDPE/LLDPE Blend-Based Nanocomposites Using a Mixture of HDPE-g-MA and LLDPE-g-MA as Compatibilizer. Polym. Eng. Sci. 2016, 56, 765-775.

16. Passador, F.R.; Ruvolo-Filho, A.C.; Pessan, L.A. Influence of blending protocol on the thermal and mechanical properties of hdpe/lldpe blend-based nanocomposites. AIP Conf. Proc. 2014, 1593, 278-281.

17. Chang, M.-K. Journal of Industrial and Engineering Chemistry Mechanical properties and thermal stability of low-density polyethylene grafted maleic anhydride/montmorillonite nanocomposites. J. Ind. Eng. Chem. 2015, 27, 96-101. [CrossRef]

18. Spencer, M.W.; Cui, L.; Yoo, Y.; Paul, D.R. Morphology and properties of nanocomposites based on HDPE/HDPE-g-MA blends. Polymer 2010, 51, 1056-1070. [CrossRef]

19. Hotta, S.; Paul, D.R. Nanocomposites formed from linear low density polyethylene and organoclays. Polymer 2004, 45, 7639-7654. [CrossRef]

20. Wilfong, D.L. Crystallization Mechanisms for LLDPE and Its Fractions. J. Polym. Sci. Part B Polym. Phys. 1990, 28, 861-870. [CrossRef]

21. Høgsaa, B.; Fini, E.H.; Christiansen, J.D.C.; Hung, A.; Mousavi, M.; Jensen, E.A.; Sanporean, C.G. A Novel Bioresidue to Compatibilize Sodium Montmorillonite and Linear Low Density Polyethylene. Ind. Eng. Chem. Res. 2018, 57, 1213-1224. [CrossRef]

22. Kumanayaka, T.O.; Parthasarathy, R.; Jollands, M. Accelerating effect of montmorillonite on oxidative degradation of polyethylene nanocomposites. Polym. Degrad. Stab. 2010, 95, 672-676. [CrossRef]

23. da Silva, D.J.; Wiebeck, H. CARS-PLS regression and ATR-FTIR spectroscopy for eco-friendly and fast composition analyses of LDPE/HDPE blends. J. Polym. Res. 2018, 25, 112. [CrossRef]

24. Sclavons, M.; Franquinet, P.; Carlier, V.; Verfaillie, G.; Fallais, I.; Legras, R.; Thyrion, F.C. Quantification of the maleic anhydride grafted onto polypropylene by chemical and viscosimetric titrations, and FTIR spectroscopy. Polymer 2000, 41, 1989-1999. [CrossRef]

25. Smith, A.L. Applied Infrared Spectroscopy, Fundamentals, Techniques, and Analytical Problem Solving; Wiley: New York, NY, USA, 1979; Volume 54.

26. Zhang, J.; Gupta, R.K.; Wilkie, C.A. Controlled silylation of montmorillonite and its polyethylene nanocomposites. Polymer 2006, 47, 4537-4543. [CrossRef] 
27. Xie, L.; Lv, X.Y.; Han, Z.J.; Ci, J.H.; Fang, C.Q.; Ren, P.G. Preparation and Performance of High-Barrier Low Density Polyethylene/Organic Montmorillonite Nanocomposite. Polym. Plast. Technol. Eng. 2012, 51, 1251-1257. [CrossRef]

28. Baur, E.; Osswald, T.A.; Rudolph, N.; Baur, E.; Osswald, T.A.; Rudolph, N. Plastics Handbook: The Resource for Plastics Engineers, 5th ed.; Carl Hanser Verlag GmbH Co KG: München, Germany, 2019; pp. I-XXI.

29. David, D.; Moreno, P.; Saron, C. Low-density polyethylene waste/recycled wood composites. Compos. Struct. 2017, 176, 1152-1157.

30. Lee, D.; Kim, H.; Yoon, K.; Eun, K. Polyethylene/MMT nanocomposites prepared by in situ polymerization using supported catalyst systems. Sci. Technol. Adv. Mater. 2005, 6, 457-462. [CrossRef]

31. Chrissopoulou, K.; Altintzi, I.; Anastasiadis, S.H.; Giannelis, E.P.; Pitsikalis, M. Controlling the miscibility of polyethylene/layered silicate nanocomposites by altering the polymer/surface interactions. Polymer 2005, 46, 12440-12451. [CrossRef]

32. Golebiewski, J.; Rozanski, A.; Dzwonkowski, J.; Galeski, A. Low density polyethylene-montmorillonite nanocomposites for film blowing. Eur. Polym. J. 2008, 44, 270-286. [CrossRef]

33. Passador, F.R. Avaliação de sistemas compatibilizantes nas correlações entre processamento e propriedades térmicas, mecânicas e de transporte em nanocompósitos de blenda HDPE/LLDPE e OMMT. Ph.D. Thesis, Universidade Federal de São Carlos, São Carlos, Brazil, 2012.

34. Liu, S.; Tu, L. Studies on mechanical properties of dispersing intercalated silane montmorillonite in low density polyethylene matrix. Int. Commun. Heat Mass Transf. 2011, 38, 879-886. [CrossRef]

35. Opelt, C.V.; Coelho, L.A.F. Reinforcement and toughening mechanisms in polymer nanocomposites-Reinforcement effectiveness and nanoclay nanocomposites. Mater. Chem. Phys. 2016, 169, 179-185. [CrossRef]

36. Varghai, D.; Maiorana, A.; Meng, Q.; Gross, R.A.; Manas-Zloczower, I. Sustainable, electrically-conductive bioepoxy nanocomposites. Polymer 2016, 107, 292-301. [CrossRef]

37. Guan, Y.; Zhong, Q. Stable aqueous foams created with intercalated montmorillonite nanoclay coated by sodium caseinate. J. Food Eng. 2019, 248, 36-45. [CrossRef]

(C) 2019 by the authors. Licensee MDPI, Basel, Switzerland. This article is an open access article distributed under the terms and conditions of the Creative Commons Attribution (CC BY) license (http://creativecommons.org/licenses/by/4.0/). 